\title{
Tax Policy and Local Labor Market Behavior
}

\author{
Daniel G. Garrett \\ Duke University
}

\author{
Eric Ohrn \\ Grinnell College
}

\author{
Juan Carlos Suárez Serrato \\ Duke University \& NBER
}

May 2019

\section{A Online Appendix: Not For Publication}

This Online Appendix includes additional information on the data and methods used in the paper as well as supplementary results. Appendix B contains additional details on our data sources. Appendix $C$ lists results from robustness checks that are mentioned in the body of the paper. Online Appendix D discusses the role of tax losses and Section 179 expensing rules in the interpretation

of our results. Appendix E shows that we obtain similar results when we analyze the effects of bonus depreciation on the employment-to-population ratio. Finally, additional tables and figures are included in Appendix F. 


\title{
B Variable Definitions
}

\author{
Variable name Definition \\ Accelerated Depreciation Variables \\ Industry We define the industry at the 4-digit NAICS level and 3-digit NAICS level in \\ different cases and denote the difference by mentioning the number of digits. \\ Employment Number of average workers listed in a geographic area and industrial grouping \\ in a given year according to ?, annual_avg_emplvl. \\ Duration The present value of depreciation deductions for the average asset in which \\ each industry invests from ?. \\ Long Duration Share of employment in each county in industries in the top tercile of indus- \\ Exposure tries as ranked by duration of average investment. This variable is always \\ normalized to the interquartile range (IQR).

\section{Other Outcome Variables} \\ Earnings Total payments made to workers in a geographic area and industrial grouping \\ in a given year according to ?, total_annual_wages. \\ Earnings-per- Total payments made to workers in a geographic area and industrial grouping \\ Worker \\ in a given year divided by employment. From ?, this variable is created as \\ total_annual_wages divided by annual_avg_emplvl.
}

\section{Other Control Variables}

$D P A D \quad$ Share of employment in each county in industries in the top tercile of industries as ranked by Qualified Production Activities Income as a percent of sales in 2005 derived from data compiled in ?.

Trade (China) County-level exposure to trade from China from ?.

Trade (NAFTA) County-level exposure to trade related to NAFTA from ?.

Routine Jobs County-level share of routine labor from ?.

Capital Stock Total capital stock, including structures, equipment, and intellectual property products, in 2001 from ? allocated to counties using employment shares at the 3-digit NAICS level.

IP Stock Total intellectual property products in 2001 from ? allocated to counties using employment shares at the 3-digit NAICS level.

Demographics County-level education outcomes including percent of population with college degrees and with less than a high school education as well as racial demographics percent white and black from the American Community Survey. Data compiled in ?. 


\section{Additional Results}

This appendix describes tables and figures that report additional details of the specifications in Figure 2, as well as additional results.

- Descriptive Statistics. We include several figures and tables to more completely describe the variation in duration both across space and across industries that we use as identifying variation in exposure to accelerated depreciation.

- Figure F3 provides a summary description of the source of employment in long duration industries.

- A map of the geographic distribution of long duration industries without normalizing within-state means to zero is shown in Figure F4.

- Table F1 describes the within sector variation in duration as well as shares of national employment from ? and capital stock from ?. The final column shows total variation (coefficient of variation multiplied by employment weight) with the manufacturing variation normalized to be equal to one.

- A list of the top and bottom ten counties with over 100,000 population in 2001 based on the percent of their employment coming from long duration industries is shown in Table F2.

- Table F3 shows additional county descriptive statistics associated with exposure to long duration, population, and local capital stock.

- Robustness to Controls. We show the robustness of the county-level regressions of employment, earnings, and earnings-per-worker in a series of expanded results with different controls and different definitions of key variables. The primary results displayed in Figure 2 are robust to the inclusion or exclusion of the controls.

- Figures F5, F6, and F7 show the robustness of the specifications in Figure 2 to taking away the county-level controls or to removing the state-by-year fixed effects. Although the 3-digit NAICS industry-by-year fixed effects are fundamental to the identification 
strategy, the county controls and state-by-year fixed effects are included as extra controls. We show that the additional controls do not have qualitative impacts on the main results.

- Tables F4, F5, and F6 show the annual coefficients from Figure 2 for employment, earnings, and earnings-per-worker, respectively. The tables all include five specifications where column (3) is the preferred specification with state-by-year and 3-digit NAICS industry-by-year fixed effects as well as controls for county economics and demographics.

- Robustness to Definition of Exposure and Placebo Tests. We also show the robustness of the baseline results shown in Figure 2 to the definition of the long duration exposure at the county level. Instead of defining firms in the top tercile of industries ranked by duration to be "long" duration, we change the threshold to the top $25 \%$ and $40 \%$ of industries and show that the results are unchanged. We also include a placebo with exposure to long duration industries that primarily invest in structures and intellectual property, NAICS 2111, 4821, $5311,7111,7112,7211,7212$, and all of 81 , which are long duration industries with more than five times more structures and IP than equipment.

- The choice to use the percentile instead of a continuous measure of average duration is twofold: (1) the continuous measure is influenced by larger outliers in NAICS 22 that invest in much longer duration assets than any other industry, so much of the variation is driven by outliers and (2) the measurement of industry-level duration of investment is a function of assumptions on discount rates that are avoided by discretizing the set of long-duration industries. In order to check that the results are not sensitive to the decision to discretize bonus exposure, we define other cutoffs and examine the stability of the coefficients of the other exposure measures. The analogue of Figure 2 is shown using exposure to the top 25\% of long duration firms in Figure F8 and using the exposure to the top $40 \%$ of long duration firms in Figure F9.

- Tables F7, F8, and F9, show the annual coefficients from Figure 2d for employment, earnings, and earnings-per-worker, respectively. The labor market outcomes tables each include five specifications where column (3) is the preferred specification with 
state-by-year and 3-digit NAICS industry-by-year fixed effects as well as county economic and demographic controls. 


\section{Adjusting for Losses and Section 179}

This appendix discusses the role of losses and Section 179 expensing rules in interpreting our results. In particular, we clarify that the interpretation of our main result is that of an intent-totreat (ITT) effect. Our main estimate differs from the treatment on the treated (ATOT) for three reasons. First, some companies may rely on Section 179 expensing instead of bonus. Second, some companies may not take up the incentives of bonus depreciation if they plan to report tax losses. A third complication is that bonus depreciation has varied in intensity across our time period. This section clarifies the interpretation of our results in light of these three factors.

We make three related points in this appendix:

1. First, accounting for Section 179 has small effects on our reduced-form estimates of the effects of bonus depreciation. Specifically, our estimates would be $11 \%$ smaller in the absence of Section 179 expensing.

2. Second, accounting for the fraction of firms with losses implies that the ATOT would be 33\% larger than the ITT. Accounting for both losses and Section 179 results in estimates of the ATOT that are $19 \%$ larger than our ITT estimates.

3. Finally, we show that the time-pattern of losses and Section 179 expensing limits has negligible effects on the time-path of our reduced-form effects in Figure 2.

\section{Marginal Investment Incentives with Losses and Section 179}

As noted by ?, the effects of bonus depreciation interact with two important factors. The first is corporate losses. Since firms can only get the immediate benefit from the bonus depreciation deduction if they owe corporate taxes, we would expect to find smaller effects when a larger fraction of firms experience year-end losses. Second, Section 179 allows firms to fully expense capital investments if the investment value is below a given threshold. A higher Section 179 limit could therefore confound the effects of bonus.

In order to explore the role of these interactions, we start by characterizing the present discounted value (PDV) of depreciation deductions. To do so, we make use of the following definitions: 
- Under the modified accelerated cost recovery system (MACRS), the PDV of depreciation deductions for the marginal dollar is $z^{0}$.

- Under Bonus, the PDV of depreciation deductions for the marginal dollar is $b+(1-b) z^{0}$. Figure D1a shows how the policy parameter $b$ varies over time. The average value of $b$ over our sample period is $39 \%$.

- Under Section 179, the PDV of depreciation deductions for the marginal dollar is 1 if $I_{j, t}<\bar{I}_{t}$, where $\bar{I}_{t}$ is the Section 179 limit. Moreover, Share $179_{t}=E\left[\mathbb{I}\left[I_{j, t}<\bar{I}_{t}\right]\right]_{t}$ is the share of investment that is eligible for Section 179 expensing. Figure D1b reports data from ? that describes the time variation in Share $179_{t}$. The Share $179_{t}$ is relatively stable over out time period with an average value that is close to $8 \%$.

- Let $\mathbb{I}\left[\right.$ Gains $\left._{j, t}\right]$ be the event that a firm is in the gains domain and Share Gains $t_{t}=E\left[\mathbb{I}\left[\text { Gains }_{j, t}\right]\right]_{t}$. Figure D1c uses data in corporate losses by industry from the IRS Statistics of Income and describes the time variation in Share Gains $t$. Over our sample period, the average value of Share Gains $t$ is close to $75 \%$.

For an individual firm $j$, the general value of depreciation deductions for the marginal dollar of investment is:

$$
\begin{aligned}
z & =\left(b+(1-b) z^{0}\right) \times\left(1-\mathbb{I}\left[I_{j, t}<\bar{I}_{t}\right]\right)+1 \times \mathbb{I}\left[I_{j, t}<\bar{I}_{t}\right] \\
& \left.=\left(b+(1-b) z^{0}\right)+\mathbb{I}\left[I_{j, t}<\bar{I}_{t}\right]\left[1-b-(1-b) z^{0}\right)\right] \\
& =\left(b+(1-b) z^{0}\right)+\mathbb{I}\left[I_{j, t}<\bar{I}_{t}\right]\left[(1-b)\left(1-z^{0}\right)\right] .
\end{aligned}
$$

Taking the difference between this value and $z^{0}$ we have :

$$
\begin{aligned}
z-z^{0} & =\left(1-z^{0}\right) b+\mathbb{I}\left[I_{j, t}<\bar{I}_{t}\right]\left[(1-b)\left(1-z^{0}\right)\right] \\
& =\left(1-z^{0}\right)\left[b+(1-b) \mathbb{I}\left[I_{j, t}<\bar{I}_{t}\right]\right] .
\end{aligned}
$$

Intuitively, Section 179 gives $b=1$ when $I_{j, t}<\bar{I}_{t}$ so the combined policy of bonus and Section 179 has a larger effect on $z-z^{0}$ whenever the event $\mathbb{I}\left[I_{j, t}<\bar{I}_{t}\right]$ is more likely. 
Assume now that a firm only values depreciation deductions in the gains domain. The average value of the shock in a county is then:

$$
\begin{aligned}
E\left[z-z^{0}\right]_{c, t} & =\left(1-z^{0}\right) \times \text { Share Gains }_{t} \times[b+(1-b) \text { Share 179 }] \\
& \approx \text { Exposure }_{c} \times \text { Share Gains }_{t} \times[b+(1-b) \text { Share 179 }]
\end{aligned}
$$

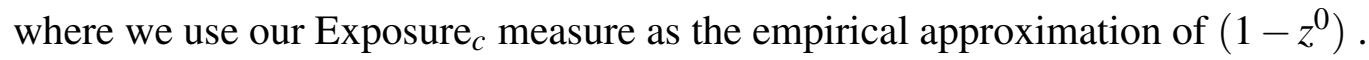

\section{Adjusting Average Reduced-Form Effects for Losses and Section 179}

Equation 1 formalizes the notion that estimates that rely on Exposure ${ }_{c}$ for identifying variation will result in estimates of intent-to-treat effects. To see this, assume average values of $b=39 \%$ and Share Gains $t=75 \%$ and temporarily ignore the role of Section 179 by setting Share $179_{t}=0$. Equation 1 then suggests that to recover the ATOT we would need to divide our estimates by Share Gains $t=75 \%$, which would increase their magnitude by $33 \%\left(\approx \frac{1}{0.75}\right)$.

To understand the role of Share $179_{t}$, assume that Share Gains $s_{t}=1$ and $b=39 \%$. To obtain the equivalent effect of an average bonus rate of $b=39 \%$ absent Section 179, we would need to multiply our estimates by: $\frac{39 \%}{39 \%+(1-39 \%) \times 8 \%} \approx 0.89$, which would make them $11 \%$ smaller. For instance, column (2) in Table 1 shows that the average increase in employment from an IQR increase in exposure to bonus depreciation was 1.9\%. Accounting for the role of Section 179, our estimate would be $1.7 \%=1.9 \% \times 0.89$.

To offset the effects of both losses and Section 179, we would have to multiply our estimates by

$\frac{39 \%}{75 \% \times[39 \%+(1-39 \%) \times 8 \%]} \approx 1.19$. The combined effect of losses and Section 179 would be to make our estimates $19 \%$ larger. Absent Section 179 and in a world where no firms were constrained in claiming bonus due to loss effects, we would expect to find an increase in employment of $2.3 \%=1.9 \% \times 1.19$.

Similarly, suppose that we are interested in evaluating the effects of a policy where $b=50 \%$ for a decade. Again, assuming no Section 179 and no frictions from corporate losses, we would expect an increase in employment of $2.9 \%=1.9 \% \times 1.52$ where $1.52=\frac{50 \%}{75 \% \times[39 \%+(1-39 \%) \times 8 \%]}$.

\section{Adjusting Dynamics of Reduced-Form Effects for Losses and Section 179}

As discussed above, while corporate losses and Section 179 expensing interact with bonus depreciation, accounting for these interactions has small effects on the interpretation of our average 
estimates. An additional concern is that the time patterns in $b$, Share Gains $t$, and Share $179_{t}$ influence the dynamics of the effects shown in Figure 2. We now perform similar adjustments as above to show that this is not the case.

Conceptually, Equation 1 shows that our treatment is time-varying, and that the intensity of the policy depends on the time patterns of $b$, Share Gains $t$, and Share $179_{t}$. The goal of this exercise is to use our estimates and the time patterns in $b$, Share Gains ${ }_{t}$, and Share $179_{t}$ from Figures D1a-D1c to compare the observed policy to a counterfactual policy where $b$, Share Gains ${ }_{t}$, and Share $179_{t}$ are held constant at their average values over our time period.

To do so, Figure D1d plots the value of the adjustment factor Share Gains ${ }_{t} \times\left[b+(1-b)\right.$ Share $\left.179_{t}\right]$ over time. This plot mostly follows the time path of $b$; however, the amplitude of the curve is diminished by Share Gains $t_{t}$ and the minimum value is augmented by Share $179_{t}$. Because outcomes in a given year $t$ are affected by the policy in previous years, we adjust our estimates by the cumulative average of Share Gains $t \times[b+(1-b)$ Share 179 $]$ from 2001 until a given year $t$. Figure D1e plots this cumulative average relative to the average value of Share Gains $s_{t} \times\left[b+(1-b)\right.$ Share $\left.179_{t}\right]$ over the time period. We can then divide our estimates in Figure 2 by the values of Figure D1e to obtain the reduced-form effects of a policy where $b$, Share Gains ${ }_{t}$, and Share $179_{t}$ are held constant at their average values over our time period. Figure D1d shows that a time-consistent policy would result in larger effects in years 2002 and 2006-2009. Similarly, this adjustment would imply smaller effects in years 2003-2004 and 2011-2012.

Figure D1f shows that adjusting our estimates on the effects of bonus depreciation on employment so that they have a time-consistent interpretation results in very similar effects. The largest change is that we observe a slightly larger effect in years 2006-2007.

Overall, the pattern of losses and Section 179 expensing do not play a material role in explaining the dynamics of how bonus depreciation affects the labor market. For this reason, we present the un-adjusted results in the paper. This result is also consistent with results in ? that show that business investment was similarly responsive to bonus depreciation in the early and latter years of our sample. 
Figure D1: Adjusting for Losses and Section 179 in the Employment Effects of Bonus Depreciation

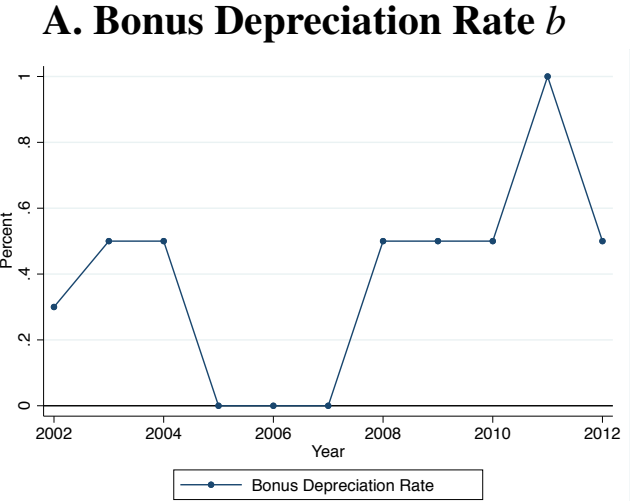

C. Fraction of Firms with Gains

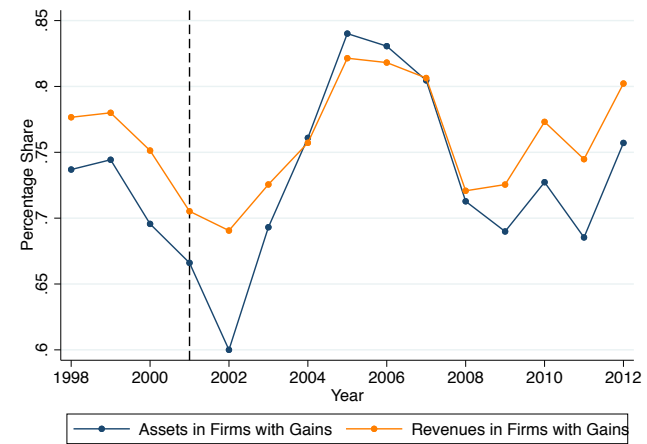

\section{E. Normalized Cumulative Average of Adjustment Factor}

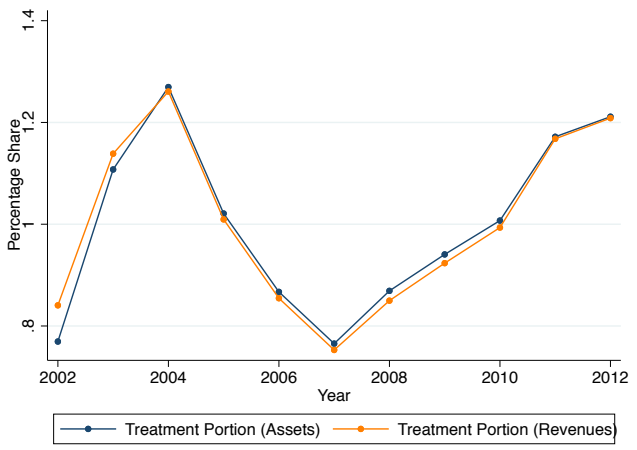

B. Fraction of $\S 179-$ Eligible Qualified Investment

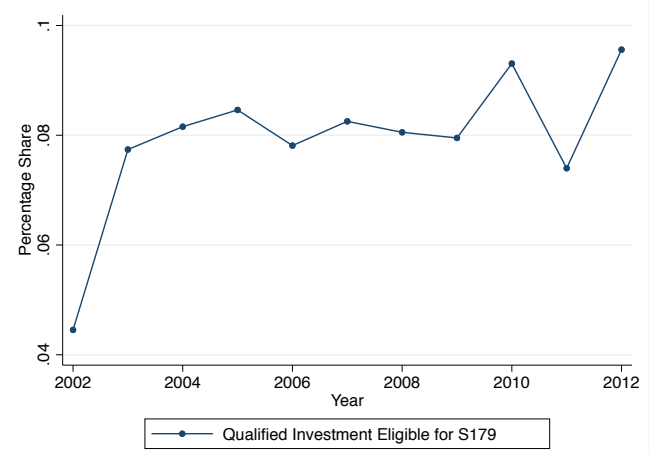

D. Adjustment Factor:

Share Gains s $_{t} \times\left[b+(1-b)\right.$ Share $\left.179_{t}\right]$

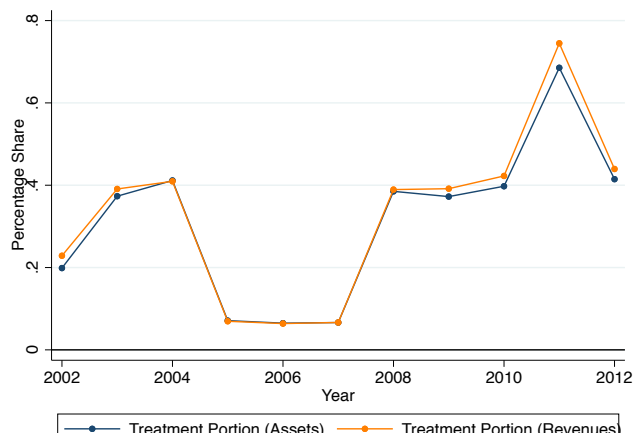

\section{F. Adjusted Effect of Bonus Depreciation on Employment}

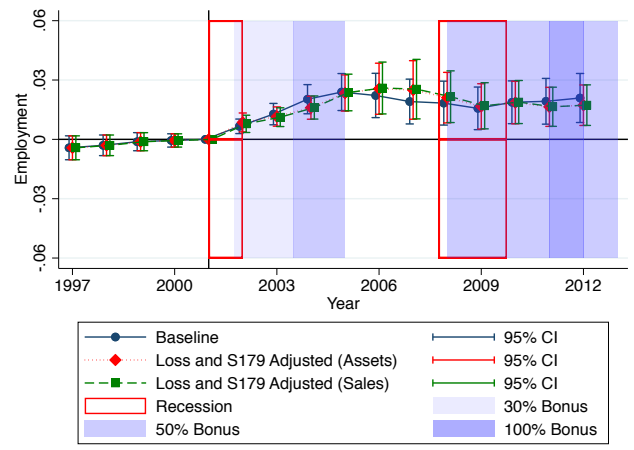

Notes: Author's calculations using employment data from QCEW, industry duration data from ?, net operating loss shares from ?, and Section 179 use from authors calculations and results reported in ?. This figure shows the annual coefficients from an event study around the implementation of bonus depreciation that is adjusted for national net operating losses and access to Section 179. Section D discusses a correction to our baseline estimates that adjusts for the intensity of treatment from Bonus in a given year due to interactions with losses and Section 179. Figure D1a shows the bonus rate $b$ for each year. Figure D1b shows the fraction of total investment that is eligible for Section 179 deductions. Figure D1c shows the percent of assets and revenues in firms that do not have losses. Figures D1a, D1b, and D1c combine into Figure D1d, the adjustment factor, and Figure D1e, the normalized cumulative average adjustment factor. Dividing the regression results from Figure 2a by the adjustment factor yields the adjusted effect of Bonus on Employment shown in Figure D1f. 


\section{E Effects of Bonus Depreciation on the Employment-to-Population Ratio}

One potential mechanism behind the increase in employment is the geographic relocation of workers. In order to account for this factor, we estimate the effects of our shock on the employment-topopulation ratio, as in ?.

Figure E2 plots the results of this analysis and shows that, similar to Figure 2, the effects of bonus depreciation on employment crest in 2006. ${ }^{1}$ This figure shows that, by 2006, a unit IQR increase in Exposure increases the employment-to-population ratio by 1 percentage point.

Overall, the average effect for years 2003-2012 is that a unit IQR increase in Exposure raised the employment-to-population ratio by 0.76 percentage points. Relative to the average US workingage population during our period of 195 million, this implies that the average effect of Exposure would be to raise employment by 4.06 million jobs. Comparing this employment effect with the cost of the policy implies a cost-per-job of $\$ 73,000\left(\approx \frac{297.5}{4.06}\right)$.

Our discussion in the paper focuses on the cost of creating a job in a given location. For this reason, our main estimate of $\$ 53,000$ is smaller than the estimate of $\$ 73,000$, which applies to the cost of creating a job relative to a given population. We choose to focus on the percentage change in employment since this outcome is comparable to previous work on local fiscal multipliers.

Finally, it is worth noting that the dynamics of the effects of bonus depreciation in Figure E2 are similar those of our main result in Figure 2. Specifically, bonus depreciation has temporary effects on employment. While these level effects are persistent, bonus depreciation does not lead to sustained increases in the rate of employment growth.

\footnotetext{
${ }^{1}$ These regressions use the county-year outcome as the unit of observations, which does not allow us to control for industry by year fixed effects. For details regarding this specification, see Appendix F of an earlier version of this article in NBER Working Paper 25546.
} 
Figure E2: Effects of Bonus Depreciation on Employment-to-Population Ratio

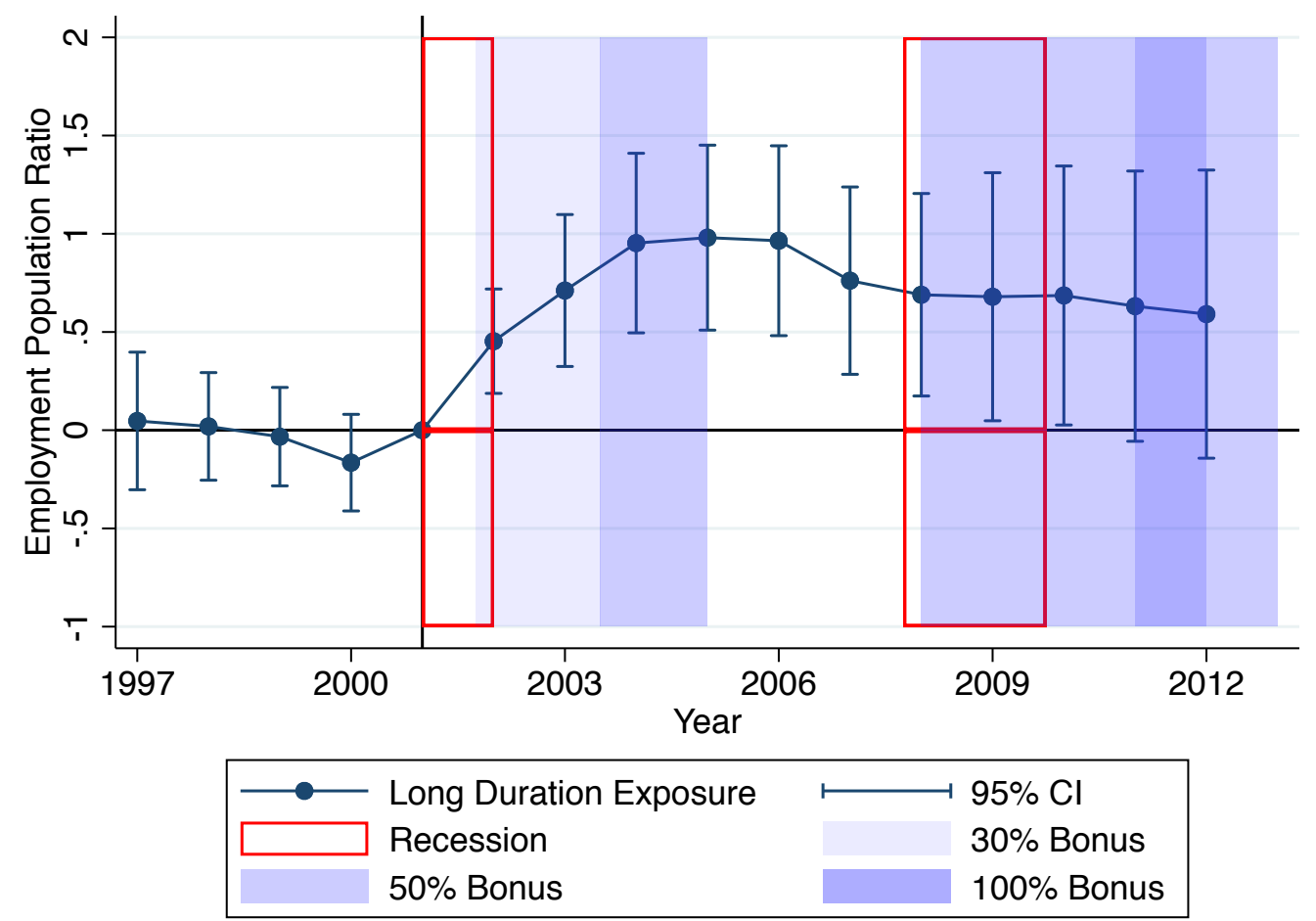

Note: Author's calculations using data from QCEW and ?. This figure shows the annual coefficients from an event study around the implementation of bonus depreciation. The dependent variable is the change in in the Employmentto-Population ratio. The variable of interest is the percent of employment that is resides in long duration industries normalized to the interquartile range (IQR). For more information on this calculation, see Appendix E. Standard errors are clustered at the county level. 


\section{F Additional Figures and Tables}




\section{Figure F3: Percent of Long Duration Employment Derived from Each 2-digit NAICS}

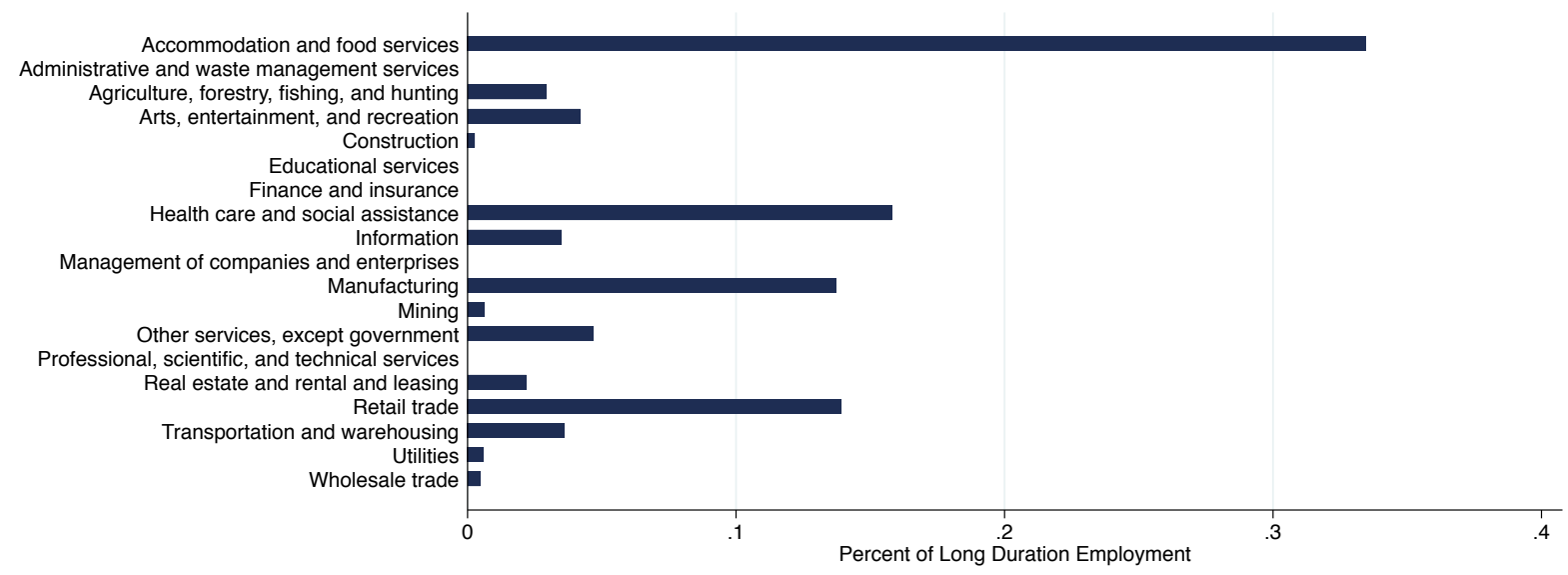

Note: Author's calculations using data from QCEW and ?. This figure shows the percent of long duration employment coming from each sector as defined by 2-digit NAICS in 2001. Data are at the national level.

Figure F4: Exposure to Long Duration Industries in 2001, Raw

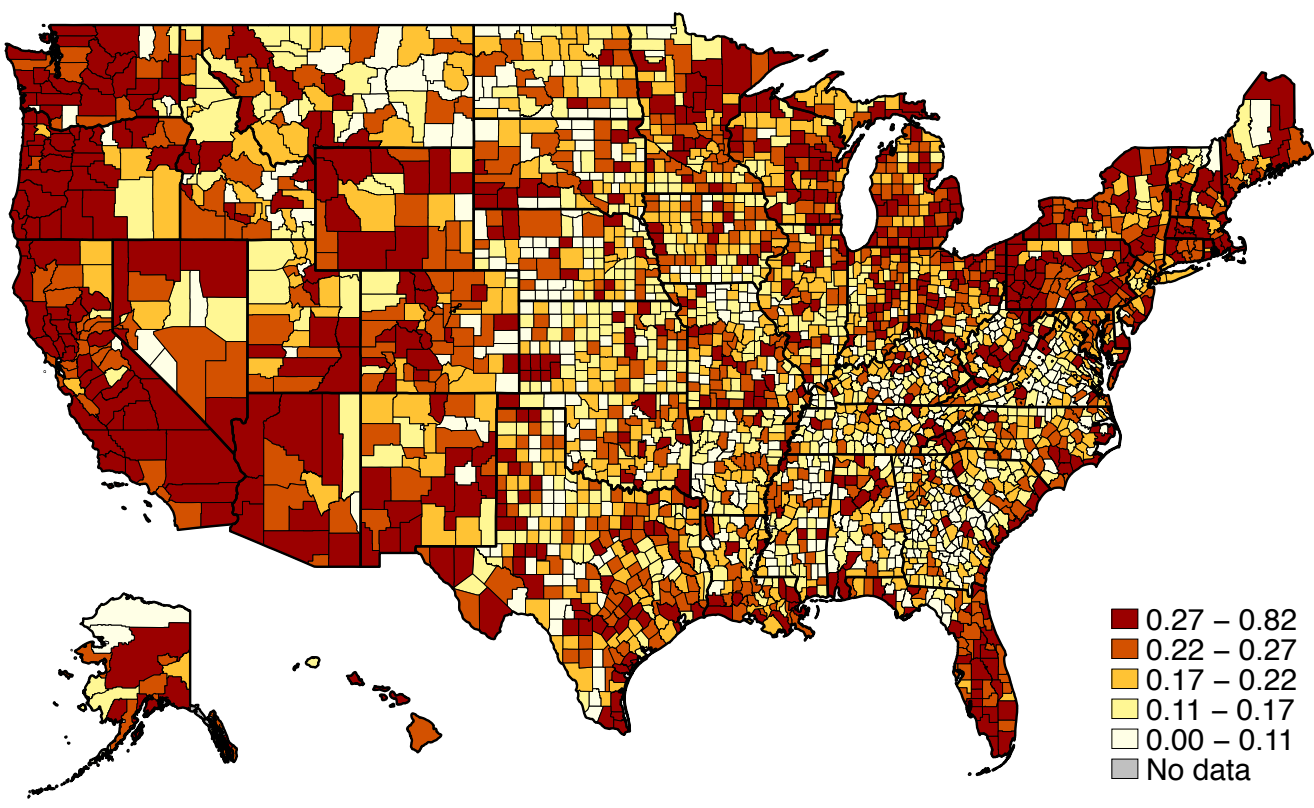

Note: Author's calculations using data from QCEW and ?. This figure shows the percent of employment in each county that comes from the top three deciles of employment-weighted industries by average duration of investment. Industries are defined by 4-digit NAICS codes. A version of this map normalized to standard deviations from statelevel mean is shown in Figure 1b. 
Figure F5: Employment Effects of Bonus Depreciation, Controls Robustness

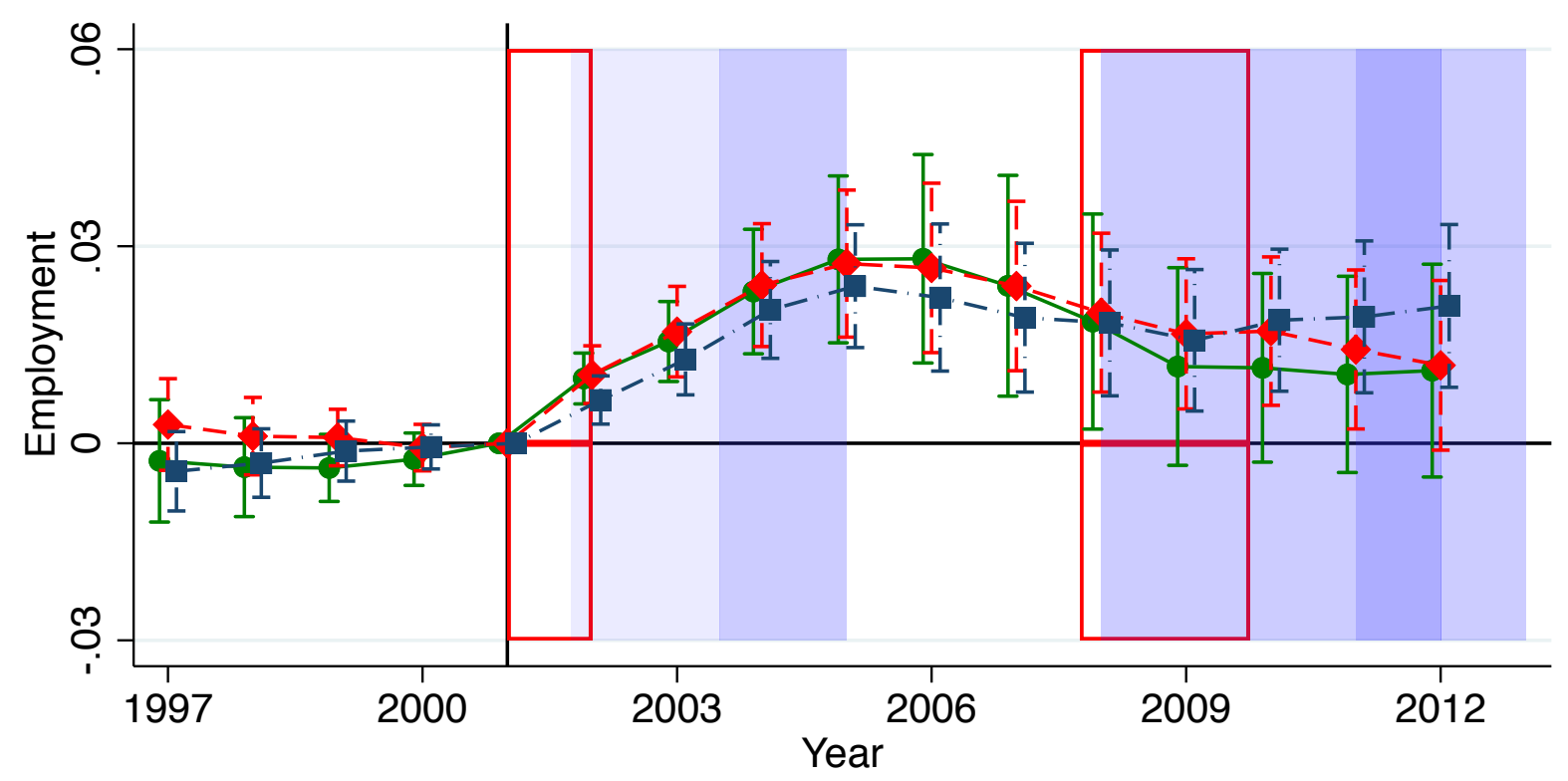

Note: Author's calculations using data from QCEW and ?. This figure shows the annual coefficients from an event study around the implementation of bonus depreciation. The dependent variable in Figure F5 is employment relative to 2001. The covariate of interest is exposure to long duration, as in Figure 2a. The coefficients and additional specifications for Figure F5 are shown in Table F4. See Appendix C for additional discussion about the importance of controls. Standard errors are clustered at the county level. 
Figure F6: Earnings Effects of Bonus Depreciation, Controls Robustness

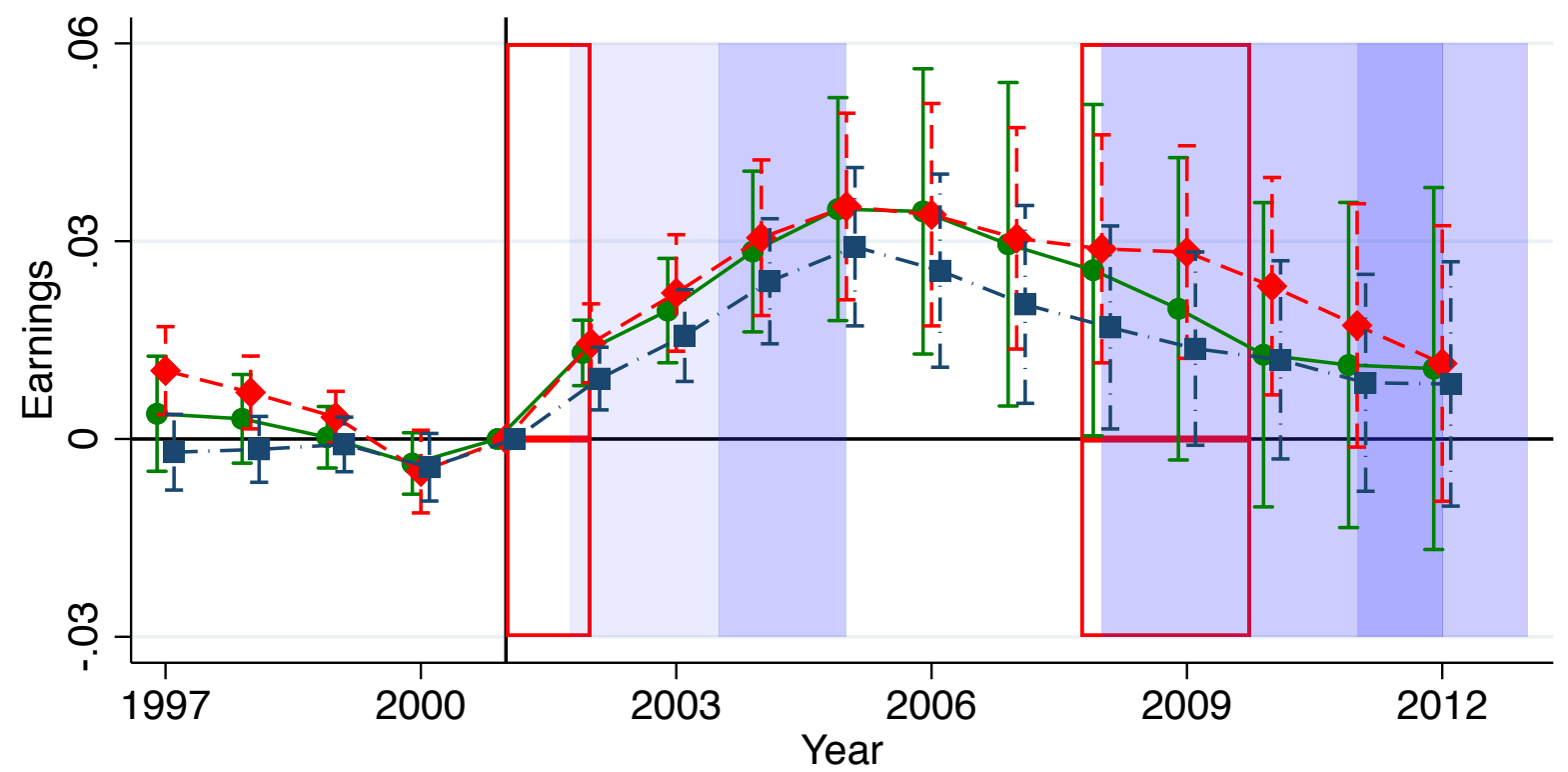

Note: Author's calculations using data from QCEW and ?. This figure shows the annual coefficients from an event study around the implementation of bonus depreciation. The dependent variable in Figure F6 is earnings relative to 2001. The covariate of interest is exposure to long duration, as in Figure 2b. The coefficients and additional specifications for Figure F6 are shown in Table F5. See Appendix C for additional discussion about the importance of controls. Standard errors are clustered at the county level. 
Figure F7: Earnings-per-Worker Effects of Bonus Depreciation, Controls Robustness

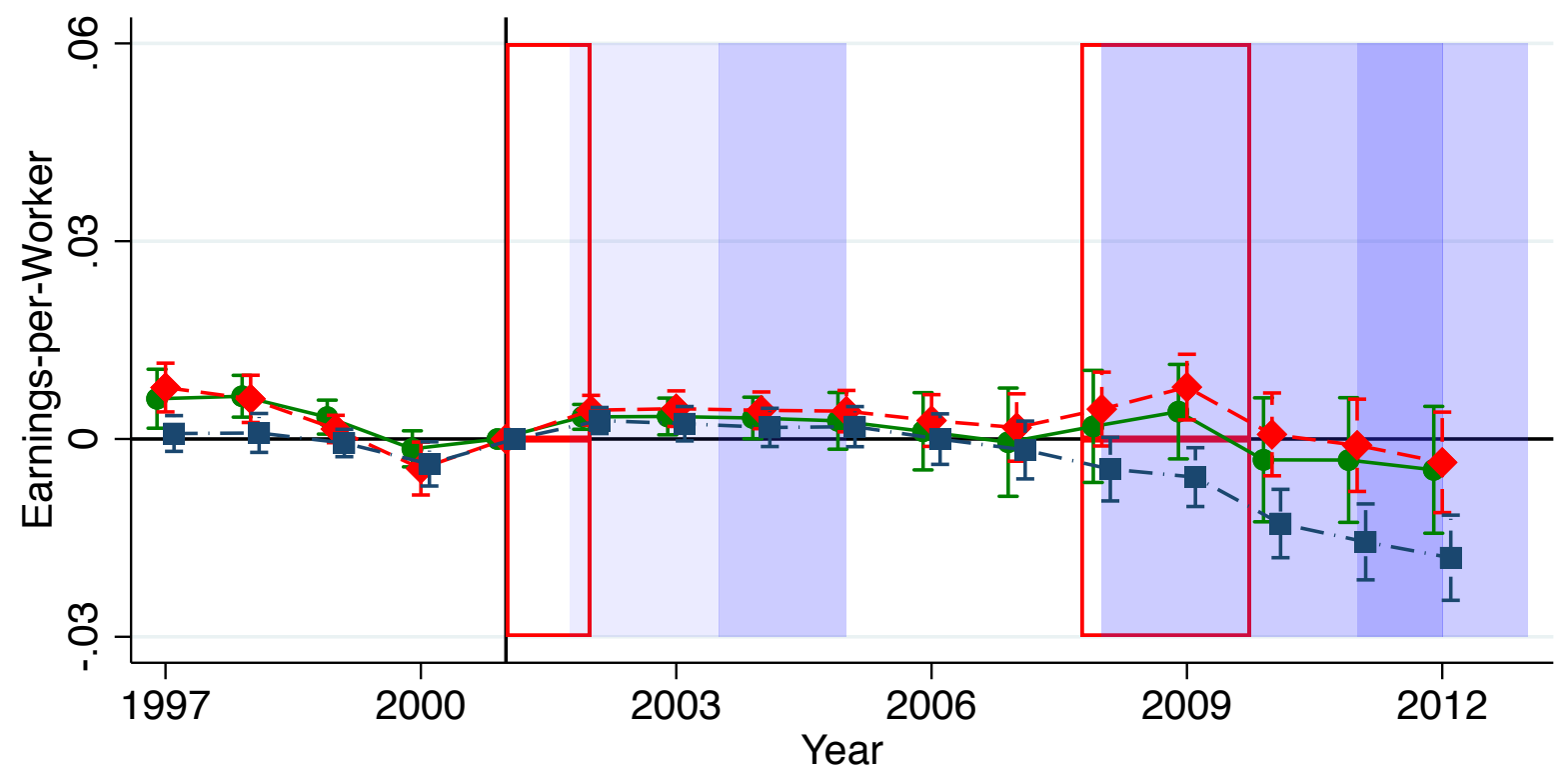

$$
\begin{array}{lr}
\longrightarrow-\text { 3-digit NAICS-by-Year FE } & \vdash 95 \% \mathrm{Cl} \\
--\checkmark-- \text { 3-digit NAICS- and State-by-Year FE } & ----\dashv 95 \% \mathrm{Cl} \\
-\neg-\text { FE and County Controls } & ---\dashv 95 \% \mathrm{Cl} \\
\hline \text { Recession } & 30 \% \text { Bonus } \\
\text { 50\% Bonus } & 100 \% \text { Bonus }
\end{array}
$$

Note: Author's calculations using data from QCEW and ?. This figure shows the annual coefficients from an event study around the implementation of bonus depreciation. The dependent variable in Figure F7 is earnings-per-worker relative to 2001. The covariate of interest is exposure to long duration, as in Figure 2c. The coefficients and additional specifications for Figure F7 are shown in Table F6. See Appendix C for additional discussion about the importance of controls. Standard errors are clustered at the county level. 
Figure F8: Effects of Bonus Depreciation by Exposure to Long Duration Industries, Long Duration Cutoff at 25\%

\section{A. Employment}

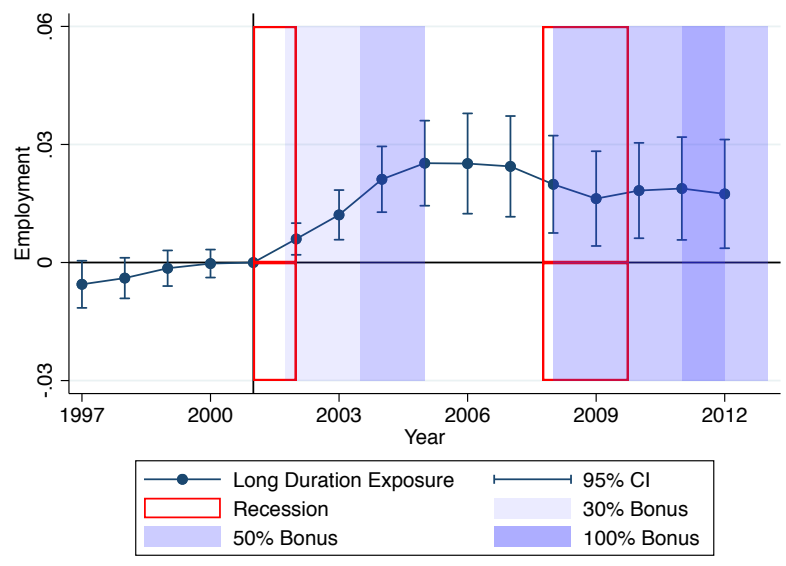

B. Earnings

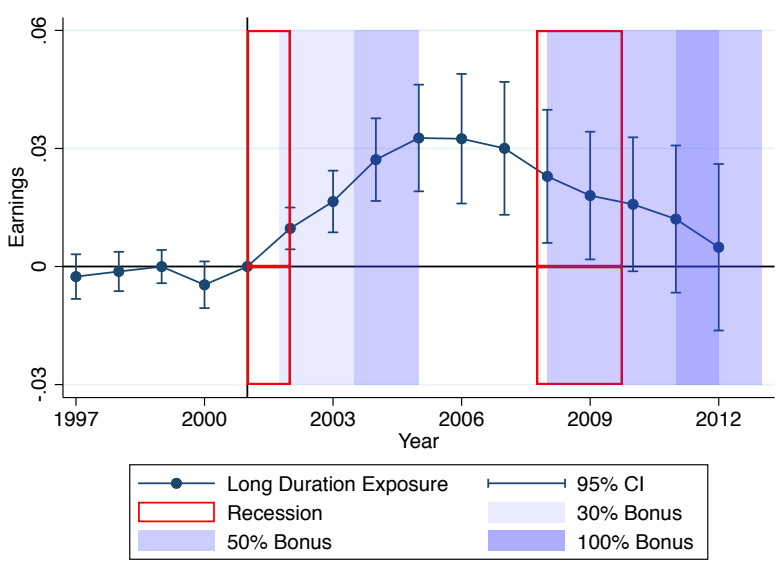

\section{Earnings-per-Worker}

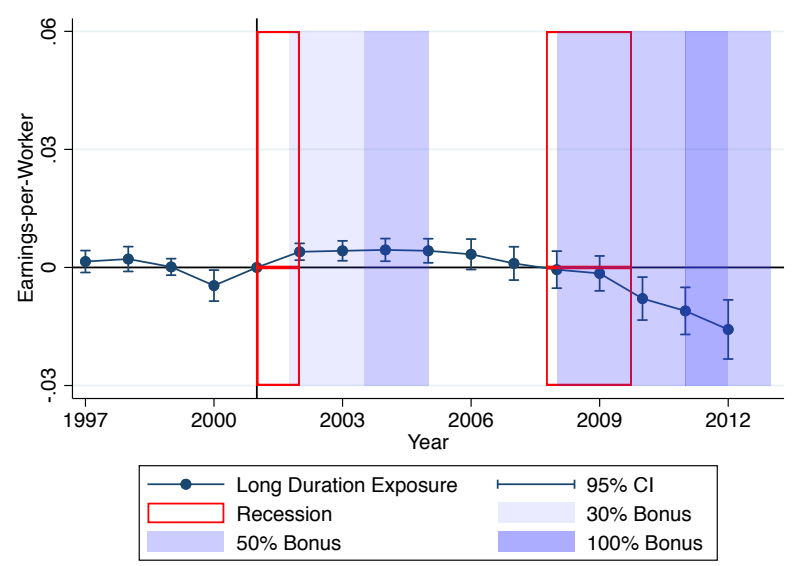

Note: Author's calculations using data from QCEW and ?. This figure shows the annual coefficients from an event study around the implementation of bonus depreciation. The dependent variable is Employment in Figure F8a, Earnings in Figure F8b and Earnings-per-Worker in Figure F8c. The variable of interest is the percent of employment that is resides in long duration industries normalized to the interquartile range (IQR). These regressions correspond to those displayed in Figure 2 with long duration industries defined at the 25\% cutoff instead of $33 \%$. 
Figure F9: Effects of Bonus Depreciation by Exposure to Long Duration Industries, Long Duration Cutoff at $40 \%$

\section{A. Employment}

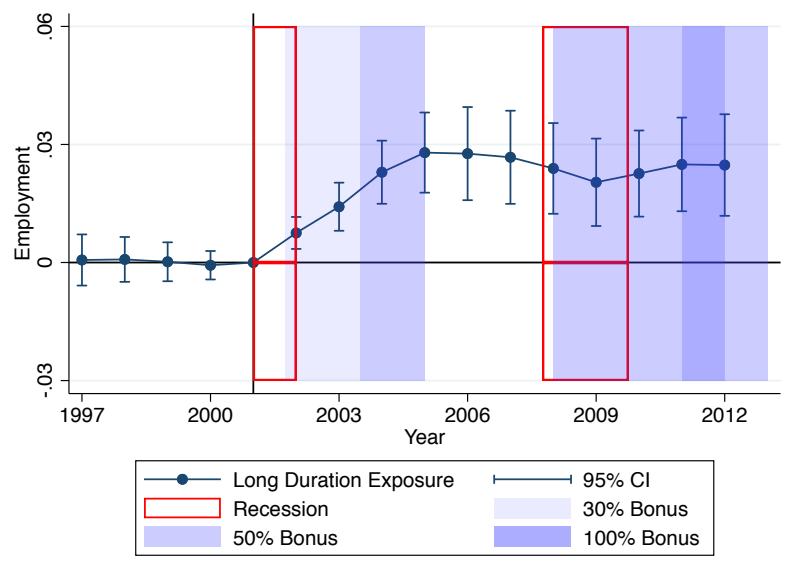

B. Earnings

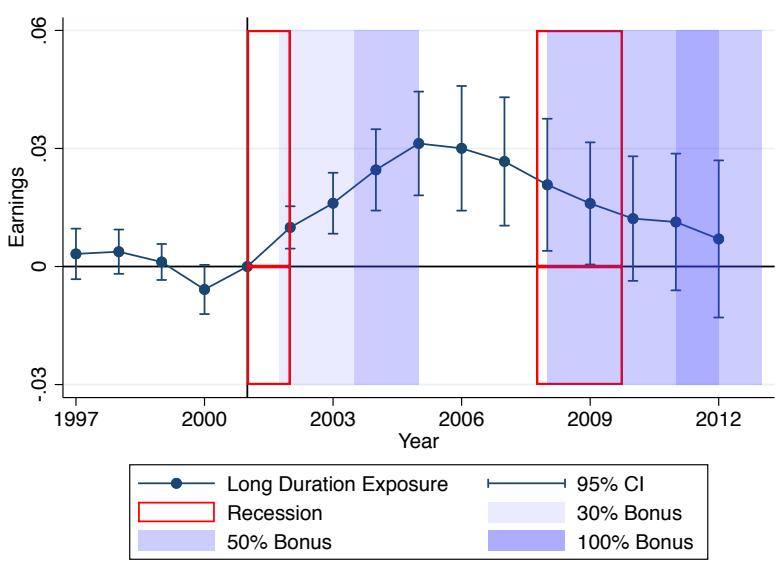

\section{Earnings-per-Worker}

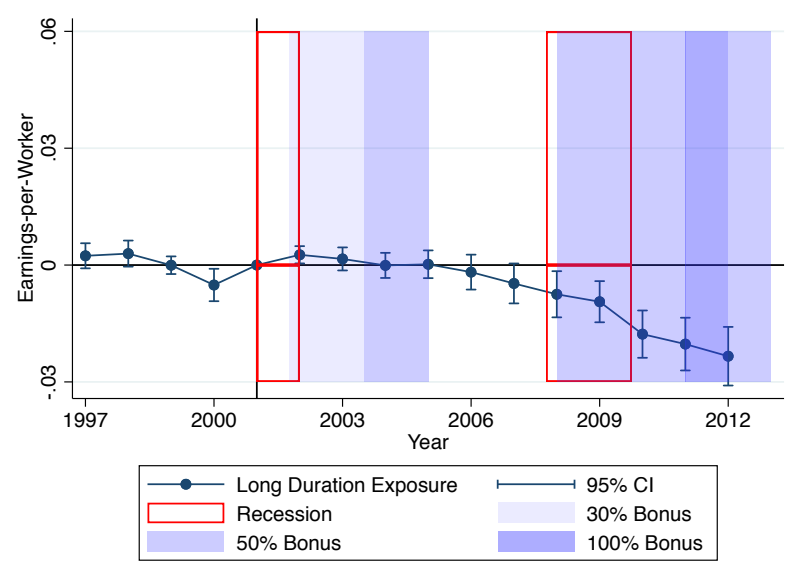

Note: Author's calculations using data from QCEW and ?. This figure shows the annual coefficients from an event study around the implementation of bonus depreciation. The dependent variable is Employment in Figure F9a, Earnings in Figure F9b and Earnings-per-Worker in Figure F9c. The variable of interest is the percent of employment that is resides in long duration industries normalized to the interquartile range (IQR). These regressions correspond to those displayed in Figure 2 with long duration industries defined at the 40\% cutoff instead of $33 \%$. 
Table F1: Characteristics of Investment Duration by Sector

\begin{tabular}{lccccccc}
\hline \hline NAICS & Industry & Average & SD & CV & Employment & Capital & Variation \\
\hline 11 & Agriculture, forestry, fishing, and hunting & 0.862 & 0.010 & 1.160 & 0.945 & 3.658 & 0.116 \\
21 & Mining & 0.881 & 0.008 & 0.940 & 0.382 & 2.353 & 0.038 \\
22 & Utilities & 0.767 & 0.032 & 4.110 & 0.183 & 6.613 & 0.079 \\
23 & Construction & 0.894 & 0.003 & 0.320 & 7.300 & 3.183 & 0.247 \\
$31-33$ & Manufacturing & 0.880 & 0.008 & 0.870 & 10.892 & 24.917 & 1.000 \\
42 & Wholesale trade & 0.888 & 0.004 & 0.450 & 5.295 & 4.875 & 0.251 \\
$44-45$ & Retail trade & 0.881 & 0.009 & 1.010 & 15.518 & 3.929 & 1.654 \\
$48-49$ & Transportation and warehousing & 0.890 & 0.016 & 1.830 & 3.633 & 9.191 & 0.702 \\
51 & Information & 0.879 & 0.018 & 2.070 & 3.033 & 10.031 & 0.663 \\
52 & Finance and insurance & 0.887 & 0.006 & 0.700 & 4.387 & 8.860 & 0.324 \\
53 & Real estate and rental and leasing & 0.878 & 0.019 & 2.180 & 2.157 & 7.638 & 0.496 \\
54 & Professional, scientific, and technical services & 0.893 & 0.003 & 0.300 & 7.489 & 2.527 & 0.237 \\
55 & Management of companies and enterprises & 0.880 &. &. & 1.811 & 0.928 &. \\
56 & Administrative and waste management services & 0.892 & 0.003 & 0.280 & 8.157 & 1.639 & 0.241 \\
61 & Educational services & 0.885 &. & 0.000 & 1.663 & 0.559 & 0.000 \\
62 & Health care and social assistance & 0.880 & 0.009 & 1.070 & 11.038 & 4.794 & 1.246 \\
71 & Arts, entertainment, and recreation & 0.858 & 0.015 & 1.800 & 1.393 & 0.767 & 0.265 \\
72 & Accommodation and food services & 0.870 & 0.004 & 0.460 & 10.750 & 2.148 & 0.522 \\
81 & Other services, except government & 0.876 & 0.011 & 1.250 & 3.974 & 1.389 & 0.524 \\
\hline \hline
\end{tabular}

Note: Author's calculations using data from QCEW and ?. This table shows the average duration characteristics of each 2-digit NAICS sector. The Variation column shows within-sector variation, defined as the coefficient of variation multiplied by the employment weight, relative to manufacturing in 2001 . Sector variables are calculated by aggregating data at the industry level using employment shares from QCEW. 
Table F2: List of Counties by Exposure to Long Duration Industries

\begin{tabular}{lcc}
\hline \hline Rank & County & Long Duration Employment Exposure \\
\hline 1 & Kent County, Delaware & .1132373 \\
2 & Durham County, North Carolina & .1204463 \\
3 & Forsyth County, Georgia & .1347249 \\
4 & Sullivan County, Tennessee & .1513936 \\
5 & Olmsted County, Minnesota & .1519782 \\
6 & Catawba County, North Carolina & .1568298 \\
7 & Rankin County, Mississippi & .1573195 \\
8 & Sarpy County, Nebraska & .1583619 \\
9 & New Castle County, Delaware & .1604007 \\
10 & Clayton County, Georgia & .161008 \\
508 & Clark County, Nevada & .4558978 \\
509 & Cape May County, New Jersey & .4573346 \\
510 & Merced County, California & .4581397 \\
511 & Napa County, California & .4653518 \\
512 & Fresno County, California & .471666 \\
513 & Yuma County, Arizona & .4897471 \\
514 & Monterey County, California & .4994023 \\
515 & Yakima County, Washington & .5202556 \\
516 & Tulare County, California & .5315269 \\
517 & Atlantic County, New Jersey & .5559594 \\
\hline \hline
\end{tabular}

Note: Author's calculations using data from QCEW and ?. This table lists the top ten and bottom ten major counties based on their exposure to long duration industries. This list only includes counties with more than 100,000 in population in 2000 . 
Table F3: County Level Descriptive Statistics

\begin{tabular}{lccccc}
\hline \hline & Mean & SD & $25^{\text {th }}$ & $50^{\text {th }}$ & $75^{\text {th }}$ \\
\hline Total Population, 2001 & 92217.745 & 298364.878 & 11596.000 & 25449.000 & 63130.000 \\
Total Employment & 34587.489 & 126911.918 & 2338.000 & 6426.000 & 19019.000 \\
Employment Growth, 2001-2007 & 0.053 & 0.185 & -0.040 & 0.038 & 0.122 \\
Employment Growth, 2001-2012 & 0.025 & 0.269 & -0.101 & -0.005 & 0.107 \\
$\quad$ Number of 3-Digit NAICS Industries & 36.540 & 20.004 & 20.000 & 35.000 & 50.000 \\
County Capital & & & & & \\
Equipment Stock, 2001 & 1226.515 & 5151.298 & 43.399 & 165.312 & 576.610 \\
Intellectual Property Stock, 2001 & 430.718 & 2053.905 & 4.027 & 22.121 & 133.989 \\
Exposure to Bonus Depreciation & & & & & \\
Average NPV of Depreciation (No Bonus) & 0.879 & 0.005 & 0.877 & 0.879 & 0.882 \\
Long Duration Exposure & 0.206 & 0.096 & 0.142 & 0.203 & 0.259 \\
Long Duration Exposure, 25\% & 0.168 & 0.087 & 0.111 & 0.160 & 0.210 \\
Long Duration Exposure, 40\% & 0.256 & 0.113 & 0.178 & 0.257 & 0.331 \\
Exposure to Non-Eligible Long Duration & 0.021 & 0.036 & 0.003 & 0.012 & 0.026 \\
\hline \hline
\end{tabular}

Note: Author's calculations using data from QCEW and ?. This table displays descriptive characteristics of the county level exposure to long duration industries. The Mean column displays the mean across counties and the SD column displays the standard deviation. The following three columns display the $25^{\text {th }}, 50^{\text {th }}$, and $75^{\text {th }}$ percentile of the distribution, respectively. 
Table F4: Event Study Regression of Total Employment on Exposure to Long Duration Industries

\begin{tabular}{|c|c|c|c|c|c|}
\hline Exposure to Long Duration Industries & $\overline{(1)}$ & 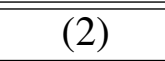 & (3) & (4) & 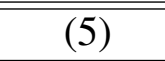 \\
\hline \multirow[t]{2}{*}{ X 1997} & -0.003 & 0.003 & -0.004 & -0.003 & 0.000 \\
\hline & $(0.005)$ & $(0.004)$ & $(0.003)$ & $(0.003)$ & $(0.004)$ \\
\hline \multirow{2}{*}{ X 1998} & -0.004 & 0.001 & -0.003 & -0.004 & 0.001 \\
\hline & $(0.004)$ & $(0.003)$ & $(0.003)$ & $(0.003)$ & $(0.004)$ \\
\hline \multirow[t]{2}{*}{ X 1999} & -0.004 & 0.001 & -0.001 & -0.003 & 0.001 \\
\hline & $(0.003)$ & $(0.002)$ & $(0.002)$ & $(0.002)$ & $(0.003)$ \\
\hline \multirow[t]{2}{*}{ X 2000} & -0.002 & -0.001 & -0.001 & -0.001 & 0.000 \\
\hline & $(0.002)$ & $(0.002)$ & $(0.002)$ & $(0.002)$ & $(0.002)$ \\
\hline \multirow[t]{2}{*}{ X 2002} & $0.010^{* * *}$ & $0.010^{* * *}$ & $0.007^{* * *}$ & $0.004^{* * *}$ & $0.008^{* * *}$ \\
\hline & $(0.002)$ & $(0.002)$ & $(0.002)$ & $(0.002)$ & $(0.002)$ \\
\hline \multirow[t]{2}{*}{ X 2003} & $0.015^{* * *}$ & $0.017^{* * *}$ & $0.013^{* * *}$ & $0.010^{* * *}$ & $0.013^{* * *}$ \\
\hline & $(0.003)$ & $(0.004)$ & $(0.003)$ & $(0.002)$ & $(0.004)$ \\
\hline \multirow[t]{2}{*}{ X 2004} & $0.023^{* * *}$ & $0.024^{* * *}$ & $0.020^{* * *}$ & $0.016^{* * *}$ & $0.020^{* * *}$ \\
\hline & $(0.005)$ & $(0.005)$ & $(0.004)$ & $(0.003)$ & $(0.005)$ \\
\hline \multirow[t]{2}{*}{ X 2005} & $0.028^{* * *}$ & $0.027^{* * *}$ & $0.024^{* * *}$ & $0.020^{* * *}$ & $0.026^{* * *}$ \\
\hline & $(0.006)$ & $(0.006)$ & $(0.005)$ & $(0.004)$ & $(0.006)$ \\
\hline \multirow[t]{2}{*}{ X 2006} & $0.028^{* * *}$ & $0.027^{* * *}$ & $0.022^{* * *}$ & $0.018^{* * *}$ & $0.024^{* * *}$ \\
\hline & $(0.008)$ & $(0.007)$ & $(0.006)$ & $(0.005)$ & $(0.008)$ \\
\hline \multirow[t]{2}{*}{ X 2007} & $0.024^{* * *}$ & $0.024^{* * *}$ & $0.019^{* * *}$ & $0.016^{* * *}$ & $0.021^{* * *}$ \\
\hline & $(0.009)$ & $(0.007)$ & $(0.006)$ & $(0.006)$ & $(0.008)$ \\
\hline \multirow[t]{2}{*}{ X 2008} & $0.019^{* *}$ & $0.020^{* * *}$ & $0.018^{* * *}$ & $0.016^{\text {*** }}$ & $0.019^{* *}$ \\
\hline & $(0.008)$ & $(0.006)$ & $(0.006)$ & $(0.006)$ & $(0.008)$ \\
\hline \multirow[t]{2}{*}{ X 2009} & 0.012 & $0.017^{* * *}$ & $0.016^{* * *}$ & $0.013^{* *}$ & $0.017^{* *}$ \\
\hline & $(0.008)$ & $(0.006)$ & $(0.005)$ & $(0.005)$ & $(0.008)$ \\
\hline \multirow[t]{2}{*}{ X 2010} & 0.011 & $0.017^{* * *}$ & $0.019^{* * *}$ & $0.016^{* * *}$ & $0.021^{* * *}$ \\
\hline & $(0.007)$ & $(0.006)$ & $(0.006)$ & $(0.005)$ & $(0.008)$ \\
\hline \multirow[t]{2}{*}{ X 2011} & 0.010 & $0.014^{* *}$ & $0.019^{* * *}$ & $0.017^{* * *}$ & $0.021^{* *}$ \\
\hline & $(0.008)$ & $(0.006)$ & $(0.006)$ & $(0.006)$ & $(0.008)$ \\
\hline \multirow[t]{2}{*}{ X 2012} & 0.011 & $0.012^{*}$ & $0.021^{* * *}$ & $0.019^{* * *}$ & $0.025^{* * *}$ \\
\hline & $(0.008)$ & $(0.007)$ & $(0.006)$ & $(0.006)$ & $(0.009)$ \\
\hline 3-digit Industry-by-Year Fixed Effects & Yes & Yes & Yes & Yes & Yes \\
\hline State-by-Year Fixed Effects & & Yes & Yes & Yes & Yes \\
\hline County Characteristics & & & Yes & Yes & Yes \\
\hline Winsorized Weights & & & & Yes & \\
\hline Drops Small County-Sectors $(<1000)$ & & & & & Yes \\
\hline
\end{tabular}

Note: Author's calculations using data from QCEW and ?. The coefficients displayed in this table come from an event study regression of total employment. The dependent variable is the percent change in total Earnings relative to 2001. The variable of interest is the percent of employment that is derived from long duration industries normalized to the interquartile range (IQR). Standard errors clustered at the county level are shown in parentheses. Column (3) is corresponds to Figure 2a.

${ }^{*} p<0.10,{ }^{* *} p<0.05,{ }^{* * *} p<0.01$. 
Table F5: Event Study Regression of Total Earnings on Exposure to Long Duration Industries

\begin{tabular}{|c|c|c|c|c|c|}
\hline Exposure to Long Duration Industries & (1) & (2) & (3) & 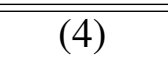 & $\overline{~(5)}$ \\
\hline \multirow{2}{*}{ X 1997} & 0.004 & $0.010^{* * *}$ & -0.002 & -0.002 & 0.001 \\
\hline & $(0.004)$ & $(0.003)$ & $(0.003)$ & $(0.003)$ & $(0.004)$ \\
\hline \multirow[t]{2}{*}{ X 1998} & 0.003 & $0.007^{* *}$ & -0.002 & -0.002 & 0.002 \\
\hline & $(0.003)$ & $(0.003)$ & $(0.003)$ & $(0.002)$ & $(0.003)$ \\
\hline \multirow[t]{2}{*}{ X 1999} & 0.000 & $0.003^{*}$ & -0.001 & -0.001 & 0.001 \\
\hline & $(0.002)$ & $(0.002)$ & $(0.002)$ & $(0.002)$ & $(0.003)$ \\
\hline \multirow[t]{2}{*}{ X 2000} & -0.004 & -0.005 & -0.004 & -0.003 & -0.005 \\
\hline & $(0.002)$ & $(0.003)$ & $(0.003)$ & $(0.002)$ & $(0.004)$ \\
\hline \multirow[t]{2}{*}{ X 2002} & $0.013^{* * *}$ & $0.015^{* * *}$ & $0.009^{* * *}$ & $0.007^{* * *}$ & $0.010^{* * *}$ \\
\hline & $(0.003)$ & $(0.003)$ & $(0.002)$ & $(0.002)$ & $(0.003)$ \\
\hline \multirow{2}{*}{ X 2003} & $0.019^{* * *}$ & $0.022^{* * *}$ & $0.016^{* * *}$ & $0.012^{* * *}$ & $0.016^{* * *}$ \\
\hline & $(0.004)$ & $(0.005)$ & $(0.004)$ & $(0.003)$ & $(0.005)$ \\
\hline \multirow[t]{2}{*}{ X 2004} & $0.028^{* * *}$ & $0.031^{* * *}$ & $0.024^{* * *}$ & $0.019^{* * *}$ & $0.024^{* * *}$ \\
\hline & $(0.006)$ & $(0.006)$ & $(0.005)$ & $(0.004)$ & $(0.006)$ \\
\hline \multirow[t]{2}{*}{ X 2005} & $0.035^{* * *}$ & $0.035^{* * *}$ & $0.029^{* * *}$ & $0.025^{\text {*** }}$ & $0.033^{* * *}$ \\
\hline & $(0.009)$ & $(0.007)$ & $(0.006)$ & $(0.006)$ & $(0.008)$ \\
\hline \multirow[t]{2}{*}{ X 2006} & $0.035^{* * *}$ & $0.034^{* * *}$ & $0.026^{* * *}$ & $0.022^{* * *}$ & $0.029^{* * *}$ \\
\hline & $(0.011)$ & $(0.009)$ & $(0.007)$ & $(0.007)$ & $(0.010)$ \\
\hline \multirow[t]{2}{*}{ X 2007} & $0.030^{* *}$ & $0.030^{* * *}$ & $0.020^{* * *}$ & $0.018^{* *}$ & $0.026^{* *}$ \\
\hline & $(0.013)$ & $(0.009)$ & $(0.008)$ & $(0.007)$ & $(0.010)$ \\
\hline \multirow[t]{2}{*}{ X 2008} & $0.026^{* *}$ & $0.029^{* * *}$ & $0.017^{* *}$ & $0.015^{* *}$ & $0.021^{*}$ \\
\hline & $(0.013)$ & $(0.009)$ & $(0.008)$ & $(0.007)$ & $(0.011)$ \\
\hline \multirow[t]{2}{*}{ X 2009} & $0.020^{*}$ & $0.028^{* * *}$ & $0.014^{*}$ & 0.011 & 0.017 \\
\hline & $(0.012)$ & $(0.008)$ & $(0.007)$ & $(0.007)$ & $(0.011)$ \\
\hline \multirow[t]{2}{*}{ X 2010} & 0.013 & $0.023^{* * *}$ & 0.012 & 0.012 & 0.016 \\
\hline & $(0.012)$ & $(0.008)$ & $(0.008)$ & $(0.007)$ & $(0.011)$ \\
\hline \multirow[t]{2}{*}{ X 2011} & 0.011 & $0.017^{*}$ & 0.009 & 0.009 & 0.013 \\
\hline & $(0.013)$ & $(0.009)$ & $(0.008)$ & $(0.008)$ & $(0.012)$ \\
\hline \multirow[t]{2}{*}{ X 2012} & 0.011 & 0.011 & 0.008 & 0.010 & 0.017 \\
\hline & $(0.014)$ & $(0.011)$ & $(0.009)$ & $(0.009)$ & $(0.013)$ \\
\hline 3-digit Industry-by-Year Fixed Effects & Yes & Yes & Yes & Yes & Yes \\
\hline State-by-Year Fixed Effects & & Yes & Yes & Yes & Yes \\
\hline County Characteristics & & & Yes & Yes & Yes \\
\hline Winsorized Weights & & & & Yes & \\
\hline Drops Small County-Sectors $(<1000)$ & & & & & Yes \\
\hline
\end{tabular}

Note: Author's calculations using data from QCEW and ?. The coefficients displayed in this table come from an event study regression of total Earnings. The dependent variable is the percent change in total earnings relative to 2001. The variable of interest is the percent of employment that is derived from long duration industries normalized to the interquartile range (IQR). Standard errors clustered at the county level are shown in parentheses. Column (3) is shown as Figure $2 b$.

${ }^{*} p<0.10,{ }^{* *} p<0.05,{ }^{* * *} p<0.01$. 
Table F6: Event Study Regression of Earnings-per-Worker on Exposure to Long Duration Industries

\begin{tabular}{|c|c|c|c|c|c|}
\hline Exposure to Long Duration Industries & (1) & (2) & (3) & (4) & (5) \\
\hline \multirow[t]{2}{*}{ X 1997} & $0.006^{* * *}$ & $0.008^{* * *}$ & 0.001 & 0.001 & -0.000 \\
\hline & $(0.002)$ & $(0.002)$ & $(0.001)$ & $(0.001)$ & $(0.002)$ \\
\hline \multirow[t]{2}{*}{ X 1998} & $0.006^{* * *}$ & $0.006^{* * *}$ & 0.001 & 0.001 & 0.001 \\
\hline & $(0.002)$ & $(0.002)$ & $(0.002)$ & $(0.001)$ & $(0.002)$ \\
\hline \multirow[t]{2}{*}{ X 1999} & $0.003^{* *}$ & 0.002 & -0.001 & 0.001 & -0.001 \\
\hline & $(0.001)$ & $(0.001)$ & $(0.001)$ & $(0.001)$ & $(0.001)$ \\
\hline \multirow[t]{2}{*}{ X 2000} & -0.001 & $-0.004^{* *}$ & $-0.004^{* *}$ & $-0.002^{*}$ & $-0.006^{* *}$ \\
\hline & $(0.001)$ & $(0.002)$ & $(0.002)$ & $(0.001)$ & $(0.002)$ \\
\hline \multirow[t]{2}{*}{ X 2002} & $0.003^{* * *}$ & $0.004^{* * *}$ & $0.003^{* * *}$ & $0.002^{* * *}$ & $0.003^{* *}$ \\
\hline & $(0.001)$ & $(0.001)$ & $(0.001)$ & $(0.001)$ & $(0.001)$ \\
\hline \multirow[t]{2}{*}{ X 2003} & $0.003^{* *}$ & $0.005^{* * *}$ & $0.002^{*}$ & 0.002 & $0.003^{*}$ \\
\hline & $(0.001)$ & $(0.001)$ & $(0.001)$ & $(0.001)$ & $(0.002)$ \\
\hline \multirow[t]{2}{*}{ X 2004} & $0.003^{* *}$ & $0.004^{* * *}$ & 0.002 & 0.002 & 0.002 \\
\hline & $(0.002)$ & $(0.001)$ & $(0.001)$ & $(0.001)$ & $(0.002)$ \\
\hline \multirow[t]{2}{*}{ X 2005} & 0.003 & $0.004^{* * *}$ & 0.002 & 0.002 & 0.003 \\
\hline & $(0.002)$ & $(0.002)$ & $(0.002)$ & $(0.002)$ & $(0.002)$ \\
\hline \multirow[t]{2}{*}{ X 2006} & 0.001 & 0.003 & -0.000 & 0.001 & 0.002 \\
\hline & $(0.003)$ & $(0.002)$ & $(0.002)$ & $(0.002)$ & $(0.003)$ \\
\hline \multirow[t]{2}{*}{ X 2007} & -0.000 & 0.002 & -0.002 & 0.000 & 0.000 \\
\hline & $(0.004)$ & $(0.003)$ & $(0.002)$ & $(0.002)$ & $(0.003)$ \\
\hline \multirow[t]{2}{*}{ X 2008} & 0.002 & 0.005 & $-0.005^{*}$ & -0.003 & -0.003 \\
\hline & $(0.004)$ & $(0.003)$ & $(0.002)$ & $(0.002)$ & $(0.003)$ \\
\hline \multirow[t]{2}{*}{ X 2009} & 0.004 & $0.008^{* * *}$ & $-0.006^{* *}$ & $-0.005^{* *}$ & -0.004 \\
\hline & $(0.004)$ & $(0.003)$ & $(0.002)$ & $(0.002)$ & $(0.003)$ \\
\hline \multirow[t]{2}{*}{ X 2010} & -0.003 & 0.001 & $-0.013^{* * *}$ & $-0.009^{* * *}$ & $-0.012^{* * *}$ \\
\hline & $(0.005)$ & $(0.003)$ & $(0.003)$ & $(0.002)$ & $(0.004)$ \\
\hline \multirow[t]{2}{*}{ X 2011} & -0.003 & -0.001 & $-0.016^{* * *}$ & $-0.012^{* * *}$ & $-0.016^{* * *}$ \\
\hline & $(0.005)$ & $(0.004)$ & $(0.003)$ & $(0.003)$ & $(0.004)$ \\
\hline \multirow[t]{2}{*}{ X 2012} & -0.005 & -0.004 & $-0.018^{* * *}$ & $-0.013^{* * *}$ & $-0.017^{* * *}$ \\
\hline & $(0.005)$ & $(0.004)$ & $(0.003)$ & $(0.003)$ & $(0.004)$ \\
\hline 3-digit Industry-by-Year Fixed Effects & Yes & Yes & Yes & Yes & Yes \\
\hline State-by-Year Fixed Effects & & Yes & Yes & Yes & Yes \\
\hline County Characteristics & & & Yes & Yes & Yes \\
\hline Winsorized Weights & & & & Yes & \\
\hline Drops Small County-Sectors $(<1000)$ & & & & & Yes \\
\hline
\end{tabular}

Note: Author's calculations using data from QCEW and ?. The coefficients displayed in this table come from an event study regression of earnings-per-worker. The dependent variable is the percent change in earnings-per-worker relative to 2001. The variable of interest is the percent of employment that is derived from long duration industries normalized to the interquartile range (IQR). Standard errors clustered at the county level are shown in parentheses. Column (3) is shown as Figure 2c.

${ }^{*} p<0.10,{ }^{* *} p<0.05,{ }^{* * *} p<0.01$. 
Table F7: Event Study Regression of Employment on Exposure to Structures Intensive Long Duration Industries (Placebo Test)

\begin{tabular}{|c|c|c|c|c|c|}
\hline Exposure to Placebo Industries & (1) & (2) & (3) & (4) & (5) \\
\hline \multirow[t]{2}{*}{ X 1997} & $-0.009^{* * *}$ & -0.002 & -0.002 & -0.002 & -0.002 \\
\hline & $(0.003)$ & $(0.002)$ & $(0.002)$ & $(0.002)$ & $(0.002)$ \\
\hline \multirow[t]{2}{*}{ X 1998} & $-0.007^{* *}$ & -0.001 & -0.001 & -0.001 & -0.000 \\
\hline & $(0.003)$ & $(0.002)$ & $(0.002)$ & $(0.002)$ & $(0.002)$ \\
\hline \multirow[t]{2}{*}{ X 1999} & $-0.005^{* * *}$ & -0.001 & -0.000 & -0.000 & 0.000 \\
\hline & $(0.002)$ & $(0.001)$ & $(0.001)$ & $(0.001)$ & $(0.001)$ \\
\hline \multirow[t]{2}{*}{ X 2000} & $-0.002^{*}$ & 0.001 & 0.001 & 0.000 & 0.001 \\
\hline & $(0.001)$ & $(0.001)$ & $(0.001)$ & $(0.001)$ & $(0.001)$ \\
\hline \multirow[t]{2}{*}{ X 2002} & 0.001 & -0.000 & -0.000 & -0.000 & -0.000 \\
\hline & $(0.001)$ & $(0.001)$ & $(0.001)$ & $(0.001)$ & $(0.001)$ \\
\hline \multirow[t]{2}{*}{ X 2003} & $0.004^{*}$ & 0.000 & 0.001 & 0.000 & 0.000 \\
\hline & $(0.002)$ & $(0.001)$ & $(0.001)$ & $(0.001)$ & $(0.001)$ \\
\hline \multirow[t]{2}{*}{ X 2004} & $0.009^{* *}$ & 0.001 & 0.002 & 0.002 & 0.001 \\
\hline & $(0.004)$ & $(0.002)$ & $(0.002)$ & $(0.002)$ & $(0.002)$ \\
\hline \multirow[t]{2}{*}{ X 2005} & $0.013^{* *}$ & 0.001 & 0.002 & 0.002 & 0.001 \\
\hline & $(0.005)$ & $(0.003)$ & $(0.002)$ & $(0.003)$ & $(0.003)$ \\
\hline \multirow[t]{2}{*}{ X 2006} & $0.016^{* *}$ & 0.001 & 0.001 & 0.001 & 0.000 \\
\hline & $(0.007)$ & $(0.004)$ & $(0.004)$ & $(0.004)$ & $(0.005)$ \\
\hline \multirow[t]{2}{*}{ X 2007} & $0.016^{* *}$ & 0.001 & -0.001 & 0.000 & -0.002 \\
\hline & $(0.007)$ & $(0.004)$ & $(0.004)$ & $(0.004)$ & $(0.005)$ \\
\hline \multirow[t]{2}{*}{ X 2008} & $0.015^{* *}$ & 0.000 & -0.001 & -0.000 & -0.002 \\
\hline & $(0.007)$ & $(0.004)$ & $(0.004)$ & $(0.004)$ & $(0.005)$ \\
\hline \multirow[t]{2}{*}{ X 2009} & $0.011^{* *}$ & -0.001 & -0.002 & -0.002 & -0.003 \\
\hline & $(0.006)$ & $(0.004)$ & $(0.004)$ & $(0.004)$ & $(0.005)$ \\
\hline \multirow[t]{2}{*}{ X 2010} & $0.010^{*}$ & -0.001 & -0.002 & -0.001 & -0.003 \\
\hline & $(0.005)$ & $(0.004)$ & $(0.004)$ & $(0.004)$ & $(0.005)$ \\
\hline \multirow[t]{2}{*}{ X 2011} & $0.010^{*}$ & -0.002 & -0.002 & -0.001 & -0.003 \\
\hline & $(0.005)$ & $(0.004)$ & $(0.004)$ & $(0.005)$ & $(0.005)$ \\
\hline \multirow[t]{2}{*}{ X 2012} & $0.010^{*}$ & -0.001 & -0.002 & -0.000 & -0.003 \\
\hline & $(0.005)$ & $(0.004)$ & $(0.004)$ & $(0.005)$ & $(0.005)$ \\
\hline 3-digit Industry-by-Year Fixed Effects & Yes & Yes & Yes & Yes & Yes \\
\hline State-by-Year Fixed Effects & & Yes & Yes & Yes & Yes \\
\hline County Characteristics & & & Yes & Yes & Yes \\
\hline Winsorized Weights & & & & Yes & \\
\hline Drops Small County-Sectors $(<1000)$ & & & & & Yes \\
\hline
\end{tabular}

Note: Author's calculations using data from QCEW and ?. The coefficients displayed in this table come from an event study regression of employment. The dependent variable is the percent change in employment relative to 2001. The variable of interest is the percent of employment that is derived from long duration industries with more than five times more structures and intellectual property than equipment normalized to the interquartile range (IQR). Standard errors clustered at the county level are shown in parentheses. Column (3) is shown in Figure 2d.

${ }^{*} p<0.10,{ }^{* *} p<0.05,{ }^{* * *} p<0.01$. 
Table F8: Event Study Regression of Total Earnings on Exposure to Structures Intensive Long Duration Industries (Placebo Test)

\begin{tabular}{|c|c|c|c|c|c|}
\hline Exposure to Placebo Industries & (1) & (2) & (3) & (4) & 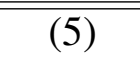 \\
\hline \multirow[t]{2}{*}{ X 1997} & 0.001 & 0.001 & 0.000 & 0.000 & 0.000 \\
\hline & $(0.001)$ & $(0.001)$ & $(0.001)$ & $(0.001)$ & $(0.001)$ \\
\hline \multirow[t]{2}{*}{ X 1998} & 0.001 & -0.001 & -0.001 & -0.001 & -0.001 \\
\hline & $(0.001)$ & $(0.001)$ & $(0.001)$ & $(0.001)$ & $(0.001)$ \\
\hline \multirow[t]{2}{*}{ X 1999} & 0.001 & -0.001 & -0.001 & -0.001 & -0.001 \\
\hline & $(0.001)$ & $(0.001)$ & $(0.001)$ & $(0.000)$ & $(0.001)$ \\
\hline \multirow[t]{2}{*}{ X 2000} & 0.000 & -0.000 & -0.000 & -0.000 & -0.001 \\
\hline & $(0.001)$ & $(0.001)$ & $(0.001)$ & $(0.000)$ & $(0.001)$ \\
\hline \multirow[t]{2}{*}{ X 2002} & 0.001 & 0.000 & 0.001 & $0.001^{*}$ & 0.001 \\
\hline & $(0.000)$ & $(0.000)$ & $(0.001)$ & $(0.000)$ & $(0.001)$ \\
\hline \multirow[t]{2}{*}{ X 2003} & 0.001 & -0.000 & -0.000 & -0.000 & -0.000 \\
\hline & $(0.001)$ & $(0.001)$ & $(0.001)$ & $(0.001)$ & $(0.001)$ \\
\hline \multirow[t]{2}{*}{ X 2004} & $0.002^{* *}$ & 0.000 & 0.000 & 0.000 & 0.000 \\
\hline & $(0.001)$ & $(0.001)$ & $(0.001)$ & $(0.001)$ & $(0.001)$ \\
\hline \multirow[t]{2}{*}{ X 2005} & $0.004^{* * *}$ & $0.002^{* *}$ & $0.002^{*}$ & $0.002^{* *}$ & 0.002 \\
\hline & $(0.001)$ & $(0.001)$ & $(0.001)$ & $(0.001)$ & $(0.001)$ \\
\hline \multirow[t]{2}{*}{ X 2006} & $0.005^{* * *}$ & $0.003^{* *}$ & 0.002 & 0.002 & 0.003 \\
\hline & $(0.001)$ & $(0.001)$ & $(0.001)$ & $(0.001)$ & $(0.002)$ \\
\hline \multirow[t]{2}{*}{ X 2007} & $0.006^{* * *}$ & $0.004^{* *}$ & 0.002 & 0.001 & 0.002 \\
\hline & $(0.002)$ & $(0.002)$ & $(0.001)$ & $(0.001)$ & $(0.002)$ \\
\hline \multirow[t]{2}{*}{ X 2008} & $0.006^{* * *}$ & $0.004^{* *}$ & 0.001 & 0.001 & 0.002 \\
\hline & $(0.002)$ & $(0.002)$ & $(0.002)$ & $(0.001)$ & $(0.002)$ \\
\hline \multirow[t]{2}{*}{ X 2009} & $0.006^{* * *}$ & $0.003^{* *}$ & -0.000 & -0.001 & 0.001 \\
\hline & $(0.002)$ & $(0.001)$ & $(0.001)$ & $(0.001)$ & $(0.002)$ \\
\hline \multirow[t]{2}{*}{ X 2010} & $0.005^{* * *}$ & $0.004^{* *}$ & -0.001 & -0.001 & 0.000 \\
\hline & $(0.002)$ & $(0.002)$ & $(0.002)$ & $(0.001)$ & $(0.002)$ \\
\hline \multirow[t]{2}{*}{ X 2011} & $0.005^{* *}$ & $0.004^{*}$ & -0.001 & -0.001 & -0.000 \\
\hline & $(0.002)$ & $(0.002)$ & $(0.002)$ & $(0.001)$ & $(0.002)$ \\
\hline \multirow[t]{2}{*}{ X 2012} & 0.003 & 0.002 & $-0.003^{*}$ & -0.002 & -0.003 \\
\hline & $(0.002)$ & $(0.002)$ & $(0.002)$ & $(0.002)$ & $(0.003)$ \\
\hline 3-digit Industry-by-Year Fixed Effects & Yes & Yes & Yes & Yes & Yes \\
\hline State-by-Year Fixed Effects & & Yes & Yes & Yes & Yes \\
\hline County Characteristics & & & Yes & Yes & Yes \\
\hline Winsorized Weights & & & & Yes & \\
\hline Drops Small County-Sectors $(<1000)$ & & & & & Yes \\
\hline
\end{tabular}

Note: Author's calculations using data from QCEW and ?. The coefficients displayed in this table come from an event study regression of total earnings. The dependent variable is the percent change in total earnings relative to 2001. The variable of interest is the percent of employment that is derived from long duration industries with more than five times more structures and intellectual property than equipment normalized to the interquartile range (IQR). Standard errors clustered at the county level are shown in parentheses. Column (3) is shown in Figure 2d.

${ }^{*} p<0.10,{ }^{* *} p<0.05,{ }^{* * *} p<0.01$. 
Table F9: Event Study Regression of Earnings Divided by Employment on Exposure to Structures Intensive Long Duration Industries (Placebo Test)

\begin{tabular}{|c|c|c|c|c|c|}
\hline Exposure to Placebo Industries & (1) & (2) & (3) & (4) & $2(5)$ \\
\hline X 1997 & $\begin{array}{c}-0.006^{* *} \\
(0.003)\end{array}$ & $\begin{array}{l}-0.001 \\
(0.002)\end{array}$ & $\begin{array}{l}-0.001 \\
(0.002)\end{array}$ & $\begin{array}{l}-0.001 \\
(0.002)\end{array}$ & $\begin{array}{l}-0.001 \\
(0.002)\end{array}$ \\
\hline \multirow[t]{2}{*}{ X 1998} & $-0.006^{* * *}$ & -0.001 & -0.002 & -0.002 & -0.001 \\
\hline & & $(0.002)$ & $(0.002)$ & $(0.002)$ & $(0.002)$ \\
\hline \multirow[t]{2}{*}{ X 1999} & $-0.004^{* * *}$ & -0.001 & -0.000 & -0.000 & -0.001 \\
\hline & $(0.001)$ & $(0.001)$ & $(0.001)$ & $(0.001)$ & $(0.001)$ \\
\hline \multirow[t]{2}{*}{ X 2000} & -0.001 & 0.001 & 0.001 & 0.000 & -0.000 \\
\hline & $(0.001)$ & $(0.001)$ & $(0.001)$ & $(0.001)$ & $(0.001)$ \\
\hline \multirow[t]{2}{*}{ X 2002} & $0.002^{*}$ & 0.000 & 0.001 & 0.000 & 0.001 \\
\hline & $(0.001)$ & $(0.001)$ & $(0.001)$ & $(0.001)$ & $(0.001)$ \\
\hline \multirow[t]{2}{*}{ X 2003} & $0.005^{* *}$ & 0.000 & 0.000 & 0.000 & 0.000 \\
\hline & $(0.003)$ & $(0.002)$ & $(0.001)$ & $(0.001)$ & $(0.002)$ \\
\hline \multirow[t]{2}{*}{ X 2004} & $0.012^{* * *}$ & 0.002 & 0.002 & 0.003 & 0.002 \\
\hline & $(0.004)$ & $(0.002)$ & $(0.002)$ & $(0.002)$ & $(0.003)$ \\
\hline \multirow[t]{2}{*}{ X 2005} & $0.019^{* * *}$ & 0.004 & 0.003 & 0.004 & 0.003 \\
\hline & $(0.007)$ & $(0.003)$ & $(0.003)$ & $(0.003)$ & $(0.004)$ \\
\hline \multirow[t]{2}{*}{ X 2006} & $0.024^{* * *}$ & 0.004 & 0.002 & 0.003 & 0.002 \\
\hline & $(0.008)$ & $(0.005)$ & $(0.004)$ & $(0.005)$ & $(0.005)$ \\
\hline \multirow[t]{2}{*}{ X 2007} & $0.027^{* * *}$ & 0.005 & 0.001 & 0.002 & 0.000 \\
\hline & $(0.009)$ & $(0.005)$ & $(0.005)$ & $(0.005)$ & $(0.006)$ \\
\hline \multirow[t]{2}{*}{ X 2008} & $0.026^{* * *}$ & 0.005 & 0.000 & 0.001 & -0.001 \\
\hline & $(0.009)$ & $(0.005)$ & $(0.005)$ & $(0.006)$ & $(0.006)$ \\
\hline \multirow[t]{2}{*}{ X 2009} & $0.020^{* * *}$ & 0.002 & -0.003 & -0.003 & -0.004 \\
\hline & $(0.008)$ & $(0.005)$ & $(0.005)$ & $(0.006)$ & $(0.006)$ \\
\hline \multirow[t]{2}{*}{ X 2010} & $0.019^{* * *}$ & 0.003 & -0.004 & -0.003 & -0.003 \\
\hline & $(0.007)$ & $(0.005)$ & $(0.005)$ & $(0.006)$ & $(0.006)$ \\
\hline \multirow[t]{2}{*}{ X 2011} & $0.019^{* * *}$ & 0.002 & -0.005 & -0.003 & -0.005 \\
\hline & $(0.007)$ & $(0.005)$ & $(0.006)$ & $(0.007)$ & $(0.007)$ \\
\hline \multirow[t]{2}{*}{ X 2012} & $0.019^{* *}$ & 0.002 & -0.005 & -0.002 & -0.006 \\
\hline & $(0.007)$ & $(0.006)$ & $(0.006)$ & $(0.007)$ & $(0.007)$ \\
\hline 3-digit Industry-by-Year Fixed Effects & Yes & Yes & Yes & Yes & Yes \\
\hline State-by-Year Fixed Effects & & Yes & Yes & Yes & Yes \\
\hline County Characteristics & & & Yes & Yes & Yes \\
\hline Winsorized Weights & & & & Yes & \\
\hline Drops Small County-Sectors $(<1000)$ & & & & & Yes \\
\hline
\end{tabular}

Note: Author's calculations using data from QCEW and ?. The coefficients displayed in this table come from an event study regression of total earnings divided by employment. The dependent variable is the percent change in total earnings divided by employment relative to 2001. The variable of interest is the percent of employment that is derived from long duration industries with more than five times more structures and intellectual property than equipment normalized to the interquartile range (IQR). Standard errors clustered at the county level are shown in parentheses. Column (3) is shown in Figure $2 \mathrm{~d}$.

${ }^{*} p<0.10,{ }^{* *} p<0.05,{ }^{* * *} p<0.01$. 